\title{
A new factor in evolution ${ }^{\dagger}$
}

\author{
James Mark Baldwin
}

In several recent publications I have developed, from different points of view, some considerations which tend to bring out a certain influence at work in organic evolution which I venture to call "a new factor." I give below a list of references ${ }^{1}$ to these publications and shall refer to them by number as this paper proceeds. The object of the present paper is to gather into one sketch an outline of the view of the process of development which these different publications have hinged upon.

The problems involved in a theory of organic development may be gathered up under three great heads: Ontogeny, Phylogeny, Heredity. The general consideration, the "factor" which I propose to bring out, is operative in the first instance, in the field of Ontogeny; I shall consequently speak first of the problem of Ontogeny, then of that of Phylogeny, in so far as the topic dealt with makes it necessary, then of that of Heredity, under the same limitation, and finally, give some definitions and conclusions.

\section{I.}

Ontogeny: "Organic Selection" (see ref. 2, chap. vii).-The series of facts which investigation in this field has to deal with are those of the individual creature's development; and two sorts of facts may be distinguished from the point of view of the functions which an organism performs in the course of his life history. There is, in the first place, the development of his heredity impulse, the unfolding of his heredity in the forms and functions which characterize his kind, together with the congenital variations which characterize the particular individual-the phylogenetic variations, which are constitutional to him; and there is, in the second place, the series of functions, acts, etc., which he learns to do himself in the course of his life. All of these latter, the special modifications which an organism undergoes during its ontogeny, thrown together, have been called "acquired characters," and we may use that expression or adopt one recently suggested by Osborn, ${ }^{2}$ "ontogenic variations" (except that I should prefer the form "ontogenetic variations"), if the word variations seems appropriate at all.

Assuming that there are such new or modified functions, in the first instance, and such "acquired characters," arising by the law of "use and disuse" from these new functions, our farther question is about them. And the question is this: How does an organism come to be modified during its life history?

In answer to this question we find that there are three different sorts of ontogenic agencies which should be distinguished-each of which works to produce ontogenetic modifications, adaptations, or

\footnotetext{
†Published in "The American Naturalist," vol. XXX, no. 354, June 1896, p. 441-451, CrossRef, and vol. XXX, no. 355, July 1896, p. 536-553, CrossRef.

${ }^{1}$ References:

(1). Imitation: a Chapter in the Natural History of Consciousness, Mind (London), Jan., 1894. Citations from earlier papers will be found in this article and in the next reference.

(2). Mental Development in the Child and the Race (1st. ed., April, 1895; 2nd ed., Oct., 1895; Macmillan \& Co. The present paper expands an additional chapter (Chap. XVII) added in the German and French editions and to be incorporated in the third English edition.

(3). Consciousness and Evolution, Science, N. Y., August, 23, 1895; reprinted in the American Naturalist, April, 1896.

(4). Heredity and Instinct (I), Science, March 20, 1896. Discussion before N. Y. Acad. of Sci., Jan. 31, 1896.

(5). Heredity and Instinct (II), Science, April 10, 1896.

(6). Physical and Social Heredity, Amer. Naturalist, May, 1896.

(7). Consciousness and Evolution, Psychol. Review, May, 1896. Discussion before Amer. Psychol. Association, Dec. $28,1895$.

${ }^{2}$ Reported in Science, April 3rd.; also used by him before N. Y. Acad. of Sci., April 13th. There is some confusion between the two terminations "genic" and "genetic." I think the proper distinction is that which reserves the former, "genic," for application in cases in which the word to which it is affixed qualifies a term used actively, while the other, "genetic" conveys similarly a passive signification; thus agencies, causes, influences, etc., and "ontogenic, phylogenic, etc.," while effects, consequences, etc., and "ontogenetic, phylogenetic, etc."
} 
variations. These are: first, the physical agencies and influences in the environment which work upon the organism to produce modifications of its form and functions. They include all chemical agents, strains, contacts, hindrances to growth, temperature changes, etc. As far as these forces work changes in the organism, the changes may be considered largely "fortuitous" or accidental. Considering the forces which produce them I propose to call them "physico-genetic." Spencer's theory of ontogenetic development rests largely upon the occurrence of lucky movements brought out by such accidental influences. Second, there is a class of modifications which arise from the spontaneous activities of the organism itself in the carrying out of its normal congenital functions. These variations and adaptations are seen in a remarkable way in plants, in unicellular creatures, in very young children. There seems to be a readiness and capacity on the part of the organism to "rise to the occasion," as it were, and make gain out of the circumstances of its life. The facts have been put in evidence (for plants) by Henslow, Pfeffer, Sachs; (for micro-organisms) by Binet, Bunge; (in human pathology) by Bernheim, Janet; (in children) by Baldwin (ref. 2, chap. vi.) (See citations in ref. 2, chap. ix, and in Orr, Theory of Development, chap. iv). These changes I propose to call "neuro-genetic," laying emphasis on what is called by Romanes, Morgan and others, the "selective property" of the nervous system, and of life generally. Third, there is the great series of adaptations secured by conscious agency, which we may throw together as "psycho-genetic". The processes involved here are all classed broadly under the term "intelligent," i.e., imitation, gregarious influences, maternal instruction, the lessons of pleasure and pain, and of experience generally, and reasoning from means to ends, etc.

We reach, therefore, the following scheme:

Ontogenetic Modifications. Ontogenic Agencies.

1. Physico-genetic......... Mechanical

2. Neuro-genetic ........2. Nervous

3. Psycho-genetic ....... 3. Intelligent

Imitation.

Pleasure and pain.

Reasoning.

Now it is evident that there are two very distinct questions which come up as soon as we admit modifications of function and of structure in ontogenetic development: first, there is the question as to how these modifications can come to be adaptive in the life of the individual creature. Or in other words: What is the method of the individual's growth and adaptation as shown in the well known law of "use and disuse?" Looked at functionally, we see that the organism manages somehow to accommodate itself to conditions which are favorable, to repeat movements which are adaptive, and so to grow by the principle of use. This involves some sort of selection, from the actual ontogenetic variations, of certain ones-certain functions, etc. Certain other possible and actual functions and structures decay from disuse. Whatever the method of doing this may be, we may simply, at this point, claim the law of use and disuse, as applicable in ontogenetic development, and apply the phrase, "Organic Selection," to the organism's behavior in acquiring new modes or modifications of adaptive function with its influence of structure. The question of the method of "Organic Selection" is taken up below (IV); here, I may repeat, we simply assume what every one admits in some form, that such adaptations of function"accommodations" the psychologist calls them, the processes of learning new movements, etc. - do occur. We then reach another question, second; what place these adaptations have in the general theory of development.

Effects of Organic Selection.-First, we may note the results of this principle in the creature's own private life.

1. By securing adaptations, accommodations, in special circumstances the creature is kept alive (ref. 2, 1 st ed., pp. $172 \mathrm{ff}$.). This is true in all the three spheres of ontogenetic variation distinguished in the table above. The creatures which can stand the "storm and stress" of the physical influences of the environment, and of the changes which occur in the environment, by undergoing modifications of their congenital functions or of the structures which they get congenitally - these creatures will live; while those which cannot, will not. In the sphere of neurogenetic variations we find a superb series of adaptations by lower as well as higher organisms during the course of ontogenetic development (ref. 2, chap. ix). And in the highest sphere, that of intelligence (including the phenomena of consciousness of all kinds, experience of pleasure and pain, imitation, etc.), we find individual accommodations on the tremendous 
scale which culminates in the skilful performances of human volition, invention, etc. The progress of the child in all the learning processes which lead him on to be a man, just illustrates this higher form of ontogenetic adaptation (ref. 2, chap. $x$-xiii).

All these instances are associated in the higher organisms, and all of them unite to keep the creature alive.

2. By this means those congenital or phylogenetic variations are kept in existence, which lend themselves to intelligent, imitative, adaptive, and mechanical modification during the lifetime of the creatures which have them. Other congenital variations are not thus kept in existence. So there arises a more or less widespread series of determinate variations in each generation's ontogenesis (ref. 3, 4, 5). ${ }^{3}$

The further applications of the principle lead us over into the field of our second question, i.e., phylogeny.

II.

Phylogeny: Physical Heredity.-The question of phylogenetic development considered apart, in so far as may be, from that of heredity, is the question as to what the factors really are which show themselves in evolutionary progress from generation to generation. The most important series of facts recently brought to light are those which show what is called "determinate variation" from one generation to another. This has been insisted on by the paleontologists. Of the two current theories of heredity, only one, Neo-Lamarckism - by means of its principle of the inheritance of acquired characters - has been able to account for this fact of determinate phylogenetic change. Weismann admits the inadequacy of the principle of natural selection, as operative on rival organisms, to explain variations when they are wanted or, as he puts it, "the right variations in the right place” (Monist, Jan., '96).
I have argued, however, in detail that the assumption of determinate variations of function in ontogenesis, under the principle of neurogenetic and psychogenetic adaptation, does away with the need of appealing to the Lamarckian factor. In the case e.g., of instincts, "if we do not assume consciousness, then natural selection is inadequate; but if we do assume consciousness, then the inheritance of acquired characters is unnecessary" (ref. 5).

"The intelligence which is appealed to, to take the place of instinct and to give rise to it, uses just these partial variations which tend in the direction of the instinct; so the intelligence supplements such partial co-ordinations, makes them functional, and so keeps the creature alive. In the phrase of Prof. Lloyd Morgan, this prevents the incidence of natural selection.' So the supposition that intelligence is operative turns out to be just the supposition which makes use-inheritance unnecessary. Thus kept alive, the species has all the time necessary to perfect the variations required by a complete instinct. And when we bear in mind that the variation required is not on the muscular side to any great extent, but in the central brain connections, and is a slight variation for functional purposes at best, the hypothesis of useinheritance becomes not only unnecessary, but to my mind quite superfluous" (ref. 4, p. 439). And for adaptations generally, "the most plastic individuals will be preserved to do the advantageous things for which their variations show them to be the most fit, and the next generation will show an emphasis of just this direction in its variations" (ref. 3, p. 221).

We get, therefore, from Organic Selection, certain results in the sphere of phylogeny:

1. This principle secures by survival certain lines of determinate phylogenetic variation in the directions of the determinate ontogenetic adaptations of the earlier generation. The variations which were utilized for ontogenetic adaptation in the earlier generation, being thus kept in existence, are utilized more widely in

\footnotetext{
3"It is necessary to consider further how certain reactions of one single organism can be selected so as to adapt the organism better and give it a life history. Let us at the outset call this process 'Organic Selection' in contrast with the Natural Selection of whole organisms .... If this (natural selection) worked alone, every change in the environment would weed out all life except those organisms, which by accidental variation reacted already in the way demanded by the changed conditions-in every case new organisms showing variations, not, in any case, new elements of life-history in the old organisms. In order to the latter we would have to conceive .... some modifications of the old reactions in an organism through the influence of new conditions .... We are, accordingly, left to the view that the new stimulations brought by changes in the environment themselves modify the reactions of an organism .... The facts show that individual organisms do acquire new adaptations in their lifetime, and that is our first problem. If in solving it we find a principle which may also serve as a principle of race-development, then we may possibly use it against the 'all sufficiency of natural selection' or in its support" (ref. 2, 1st. ed., pp. 175-6.)
} 
the subsequent generation (ref. 3, 4). "Congenital variations, on the one hand, are kept alive and made effective by their use for adaptations in the life of the individual; and, on the other hand, adaptations become congenital by further progress and refinement of variation in the same lines of function as those which their acquisition by the individual called into play. But there is no need in either case to assume the Lamarckian factor" (ref. 3). And in cases of conscious adaptation: "We reach a point of view which gives to organic evolution a sort of intelligent direction after all; for of all the variations tending in the direction of an adaptation, but inadequate to its complete performance, only those will be supplemented and kept alive which the intelligence ratifies and uses. The principle of 'selective value' applies to the others or to some of them. So natural selection kills off the others; and the future development at each stage of a species' development must be in the directions thus ratified by intelligence. So also with imitation. Only those imitative actions of a creature which are useful to him will survive in the species, for in so far as he imitates actions which are injurious he will aid natural selection in killing himself off. So intelligence, and the imitation which copies it, will set the direction of the development of the complex instincts even on the Neo-Darwinian theory; and in this sense we may say that consciousness is a 'factor"' (ref. 4).

2. The mean of phylogenetic variation being thus made more determinate, further phylogenetic variations follow about this mean, and these variations are again utilized by Organic Selection for ontogenetic adaptation. So there is continual phylogenetic progress in the directions set by ontogenetic adaptation (ref. 3, 4, 5). "The intelligence supplements slight co-adaptations and so gives them selective value; but it does not keep them from getting farther selective value as instincts, reflexes, etc., by farther variation" (ref. 5). "The imitative function, by using muscular co-ordinations, supplements them, secures adaptations, keeps the creature alive, prevents the 'incidence of natural selection,' and so gives the species all the time necessary to get the variations required for the full instinctive performance of the function" (ref. 4). But, "Conscious imitation, while it prevents the incidence of natural selection, as has been seen, and so keeps alive the creatures which have no instincts for the performance of the actions required, nevertheless does not subserve the utilities which the special in- stincts do, nor prevent them from having the selective value of which Romanes speaks. Accordingly, on the more general definition of intelligence, which includes in it all conscious imitation, use of maternal instruction, and that sort of things-no less than on the more special definition-we still find the principle of natural selection operative" (ref. 5).

3. This completely disposes of the Lamarckian factor as far as two lines of evidence for it are concerned. First, the evidence drawn from function, "use and disuse," is discredited; since by "organic selection," the reappearance, in subsequent generations, of the variations first secured in ontogenesis is accounted for without the inheritance of acquired characters. So also the evidence drawn from paleontology which cites progressive variations resting on functional use and disuse. Second, the evidence drawn from the facts of "determinate variations;" since by this principle we have the preservation of such variations in phylogeny without the inheritance of acquired characters.

4. But this is not Preformism in the old sense; since the adaptations made in ontogenetic development which "set" the direction of evolution are novelties of function in whole or part (although they utilize congenital variations of structure). And it is only by the exercise of these novel functions that the creatures are kept alive to propagate and thus produce further variations of structure which may in time make the whole function, with its adequate structure, congenital. Romanes' argument from "partial coadaptations" and "selective value," seem to hold in the case of reflex and instinctive functions (ref. 4, 5), as against the old preformist or Weismannist view, although the operation of Organic Selection, as now explained, renders them ineffective when urged in support of Lamarckism. "We may imagine creatures, whose hands were used for holding only with the thumb and fingers on the same side of the object held, to have first discovered, under stress of circumstances and with variations which permitted the further adaptation, how to make use of the thumb for grasping opposite to the fingers, as we now do. Then let us suppose that this proved of such utility that all the young that did not do it were killed off; the next generation following would be plastic, intelligent, or imitative, enough to do it also. They would use the same co-ordinations and prevent natural selection getting its operation on them; and so instinctive 
'thumb-grasping' might be waited for indefinitely by the species and then be got as an instinct altogether apart from use-inheritance" (ref. 4). "I have cited 'thumb-grasping' because we can see in the child the anticipation, by intelligence and imitation, of the use of the thumb for the adaptation which the Simian probably gets entirely by instinct, and which I think an isolated and weak-minded child, say, would also come to do by instinct" (ref. 4).

5. It seems to me also-though I hardly dare venture into a field belonging so strictly to the technical biologist-that this principle might not only explain many cases of widespread "determinate variations" appearing suddenly, let us say, in fossil deposits, but the fact that variations seem often to be "discontinuous". Suppose, for example, certain animals, varying, in respect to a certain quality, from $a$ to $n$ about a mean $x$. The mean $x$ would be the case most likely to be preserved in fossil form (seeing that there are vastly more of them). Now suppose a sweeping change in the environment, in such a way that only the variations lying near the extreme $n$ can accommodate to it and live to reproduce. The next generation would then show variations about the mean $n$. And the chances of fossils from this generation, and the subsequent ones, would be of creatures approximating $n$. Here would be a great discontinuity in the chain and also a widespread prevalence of these variations in a set direction. This seems especially evident when we consider that the paleontologist does not deal with successive generations, but with widely remote periods, and the smallest lapse of time which he can take cognizance of is long enough to give the new mean of variation, $n$, a lot of generations in which to multiply and deposit its representative fossils. Of course, this would be only the action of natural selection upon "preformed" variations in those cases which did not involve positive changes, in structure and function, acquired in ontogenesis; but in so far as such ontogenetic adaptations were actually there, the extent of difference of the $n$ mean from the $x$ mean would be greater, and hence the resources of explanation, both of the sudden prevalence of the new type and of its discontinuity from the earlier, would be much increased. This additional resource, then, is due to the "Organic Selection" factor.

We seem to be able also to utilize all the evidence usually cited for the functional origin of specific characters and groupings of characters. So far as the
Lamarckians have a strong case here, it remains as strong if Organic Selection be substituted for the "inheritance of acquired characters." This is especially true where intelligent and imitative adaptations are involved, as in the case of instinct. This "may give the reason, e.g., that instincts are so often coterminous with the limits of species. Similar structures find the similar uses for their intelligence, and they also find the same imitative actions to be to their advantage. So the interaction of these conscious factors with natural selection brings it about that the structural definition which represents species, and the functional definition which represents instinct, largely keep to the same lines" (ref. 5).

6. It seems proper, therefore, to call the influence of Organic Selection "a new factor;" for it gives a method of deriving the determinate gains of phylogeny from the adaptations of ontogeny without holding to either of the two current theories. The ontogenetic adaptations are really new, not performed; and they are really reproduced in succeeding generations, although not physically inherited.

III.

Social Heredity. - There follows also another resource in the matter of development. In all the higher reaches of development we find certain co-operative or "social" processes which directly supplement or add to the individual's private adaptations. In the lower forms it is called gregariousness, in man sociality, and in the lowest creatures (except plants) there are suggestions of a sort of imitative and responsive action between creatures of the same species and in the same habitat. In all these cases it is evident that other living creatures constitute part of the environment of each, and many neuro-genetic and psychogenetic accommodations have reference to or involve these other creatures. It is here that the principle of imitation gets tremendous significance; intelligence and volition, also, later on; and in human affairs it becomes social co-operation. Now it is evident that when young creatures have these imitative, intelligent, or quasi-social tendencies to any extent, they are able to pick up for themselves, by imitation, instruction, experience generally, the functions which their parents and other creatures perform in their presence. This then is a form of ontogenetic adaptation; it keeps these creatures alive, and so produces 
determinate variations in the way explained above. It is, therefore, a special, and from its wide range, an extremely important instance of the general principle of Organic Selection.

But it has a farther value. It keeps alive a series of functions which either are not yet, or never do become, congenital at all. It is a means of extra-organic transmission from generation to generation. It is really a form of heredity because (1) it is a banding down of physical functions; while it is not physical heredity. It is entitled to be called heredity for the further reason (2) that it directly influences physical heredity in the way mentioned, i.e., it keeps alive variations, thus sets the direction of ontogenetic adaptation, thereby influences the direction of the available congenital variations of the next generation, and so determines phylogenetic development. I have accordingly called it "Social Heredity" (ref. 2, chap. xii; ref. 3).

In "Social Heredity," therefore, we have a more or less conservative, progressive, ontogenic atmosphere of which we may make certain remarks as follows:-

(1) It secures adaptations of individuals all through the animal world. "Instead of limiting this influence to human life, we have to extend it to all the gregarious animals, to all the creatures that have any ability to imitate, and finally to all animals who have consciousness sufficient to enable them to make adaptations of their own; for such creatures will have children that can do the same, and it is unnecessary to say that the children must inherit what their fathers did by intelligence, when they can do the same things by intelligence" (ref. 6).

(2) It tends to set the direction of phylogenetic progress by Organic Selection, Sexual Selection, etc., i.e., it tends not only to give the young the adaptations which the adults already have, but also to produce adaptations which depend upon social cooperation; thus variations in the direction of sociality are selected and made determinate. "When we remember that the permanence of habit learned by one individual is largely conditioned by the learning of the same habits by others (notably of the opposite sex) in the same environment, we see that an enormous premium must have been put on variations of a social kindthose which brought different individuals into some kind of joint action or cooperation. Wherever this appeared, not only would habits be maintained, but new variations, having all the force of double hereditary tendency, might also be expected" (ref. 3). Why is it, for example, that a race of Mulattoes does not arise faster, and possess our Southern States? Is it not just the social repugnance to black-white marriages? Remove or reverse this influence of education, imitation, etc., and the result on phylogeny would show in our faces, and even appear in our fossils when they are dug up long hence by the paleontologist of the succeeding æons!

(3) In man it becomes the law of social evolution. "Weismann and others have shown that the influence of animal intercourse, seen in maternal instruction, imitation, gregarious cooperation, etc., is very important. Wallace dwells upon the actual facts which illustrate the 'imitative factor,' as we may call it, in the personal development of young animals. I have recently argued that Spencer and others are in error in holding that social progress demands useinheritance; since the socially-acquired actions of a species, notably man, are socially handed down, giving a sort of 'social heredity' which supplements natural heredity" (ref. 4). The social "sport," the genius, is very often the controlling factor in social evolution. He not only sets the direction of future progress, but he may actually lift society at a bound up to a new standard of attainment (ref. 6). "So strong does the case seem for the Social Heredity view in this matter of intellectual and moral progress that I may suggest an hypothesis which may not stand in court, but which I find interesting. May not the rise of social life be justified from the point of view of a second utility in addition to that of its utility in the struggle for existence as ordinarily understood, the second utility, i.e., of giving to each generation the attainments of the past which natural inheritance is inadequate to transmit. When social life begins, we find the beginning of the artificial selection of the unfit; and this negative principle begins to work directly in the teeth of progress, as many writers on social themes have recently made clear. This being the case, some other resource is necessary besides natural inheritance. On my hypothesis it is found in the common or social standards of attainment which the individual is fitted to grow up to and to which he is compelled to submit. This secures progress in two ways: First, by making the individual learn what the race has learned, thus preventing social retrogression, in any case; and second, by putting a direct premium on variations which are socially available" (ref. 3).

(4) The two ways of securing development in de- 
terminate directions - the purely extra-organic way of Social Heredity, and the way by which Organic Selection in general (both by social and by other ontogenetic adaptations) secures the fixing of phylogenetic variations, as described above-seem to run parallel. Their conjoint influence is seen most interestingly in the complex instincts (ref. 4, 5). We find in some instincts completely reflex or congenital functions which are accounted for by Organic Selection. In other instincts we find only partial coordinations ready given by heredity, and the creature actually depending upon some conscious resource (imitation, instruction, etc.) to bring the instinct into actual operation. But as we come up in the line of phylogenetic development, both processes may be present for the same function; the intelligence of the creature may lead him to do consciously what he also does instinctively. In these cases the additional utility gained by the double performance accounts for the duplication. It has arisen either (1) by the accumulation of congenital variations in creatures which already performed the action (by ontogenetic adaptation and handed it down socially), or (2) the reverse. In the animals, the social transmission seems to be mainly useful as enabling a species to get instincts slowly in determinate directions, by keeping off the operation of natural selection. Social Heredity is then the lesser factor; it serves Biological Heredity. But in man, the reverse. Social transmission is the important factor, and the congenital equipment of instincts is actually broken up in order to allow the plasticity which the human being's social learning requires him to have. So in all cases both factors are present, but in a sort of inverse ratio to each other. In the words of Preyer, "the more kinds of co-ordinated movement an animal bring into the world, the fewer is he able to learn afterwards." The child is an animal which inherits the smallest number of congenital coordinations, but he is the one that learns the greatest number (ref. 2, p. 297).

"It is very probable, as far as the early life of the child may be taken as indicating the factors of evolution, that the main function of consciousness is to enable him to learn things which natural heredity fails to transmit; and with the child the fact that consciousness is the essential means of all his learning is correlated with the other fact that the child is the very creature for which natural heredity gives few independent functions. It is in this field only that I venture to speak with assurance; but the same point of view has been reached by Weismann and others on the purely biological side. The instinctive equipment of the lower animal is replaced by the plasticity for learning by consciousness. So it seems to me that the evidence points to some inverse ratio between the importance of consciousness as factor in development and the need of inheritance of acquired characters as factor in development" (ref. 7).

"Under this general conception we may bring the biological phenomena of infancy, with all their evolutionary significance: the great plasticity of the mammal infant as opposed to the highly developed instinctive equipment of other young; the maternal care, instruction and example during the period of dependence, and the very gradual attainment of the activities of self-maintenance in conditions in which social activities are absolutely essential. All this stock of the development theory is available to confirm this view" (ref. 3).

But these two influences furnish a double resort against Neo-Lamarckism. And I do not see anything in the way of considering the fact of Organic Selection, from which both these resources spring, as being a sufficient supplement to the principle of natural selection. The relation which it bears to natural selection, however, is a matter of further remark below (V).

"We may say, therefore, that there are two great kinds of influence, each in a sense hereditary; there is natural heredity by which variations are congenitally transmitted with original endowment, and there is 'social heredity' by which functions socially acquired (i.e., imitatively, covering all the conscious acquisitions made through intercourse with other animals) are also socially transmitted. The one is phylogenetic; the other ontogenetic. But these two lines of hereditary influence are not separate nor uninfluential on each other. Congenital variations, on the one hand, are kept alive and made effective by their conscious use for intelligent and imitative adaptations in the life of the individual; and, on the other hand, intelligent and imitative adaptations become congenital by further progress and refinement of variation in the same lines of function as those which their acquisition by the individual called into play. But there is no need in either case to assume the Lamarckian factor" (ref. 4).

"The only hindrance that I see to the child's 
learning everything that his life in society requires would be just the thing that the advocates of Lamarckism argue for-the inheritance of acquired characters. For such inheritance would tend so to bind up the child's nervous substance in fixed forms that he would have less or possibly no unstable substance left to learn anything with. So, in fact, it is with the animals in which instinct is largely developed; they have no power to learn anything new, just because their nervous systems are not in the mobile condition represented by high consciousness. They have instinct and little else" (ref. 3).

\section{IV.}

The Process of Organic Selection.-So far we have been dealing exclusively with facts. By recognizing certain fact we have reached a view which considers ontogenetic selection an important factor in development. Without prejudicing the statement of fact at all we may enquire into the actual working of the organism is making its organic selections or adaptations. The question is simply this: how does the organism secure, from the multitude of possible ontogenetic changes which it might and does undergo, those which are adaptive? As a matter of fact, all personal growth, all motor acquisitions made by the individual, show that it succeeds in doing this; the further question is, how? Before taking this up, I must repeat with emphasis that the position taken in the foregoing pages, which simply makes the fact of ontogenetic adaptation a factor in development, is not involved in the solution of the further question as to how the adaptations are secured. But from the answer to this latter question we may get further light of the interpretation of the facts themselves. So we come to ask how Organic Selection actually operates in the case of a particular adaptation of a particular creature (ref. 1; ref. 2, chap. vii, xiii; ref. 6, and 7).

I hold that the organism has a way of doing this which is peculiarly its own. The point is elaborated at such great length in the book referred to (ref. $2)$ that I need not repeat details here. The summary in this journal (ref. 6) may have been seen by its readers. There is a fact of physiology which, taken together with the facts of psychology, serves to indicate the method of the adaptations or accommodations of the individual organism. The general fact is that the organism concentrates its energies upon the locality stimulated, for the continuation of the conditions, movements, stimulations which are vitally beneficial, and for the cessation of the conditions, movements, stimulations, which are vitally depressing and harmful. In the case of beneficial conditions we find a general increase of movement, an excess of discharge of the energies of movement in the channels already open and habitual; and with this, on the psychological side, pleasurable consciousness and attention. Attention to a member is accompanied by increased vasomotor activity, with higher muscular power, and a general dynamogenic heightening in that member. "The thought of a movement tends to discharge motor energy into the channels as near as may be to those necessary for that movement" (ref. 3). By this organic concentration and excess of movement many combinations and variations are rendered possible, from which the advantageous and adaptive movements may be selected for their utility. These then give renewed pleasure, excite pleasurable associations, and again stimulate the attention, and by these influences the adaptive movements thus struck are selected and held as permanent acquisitions. This form of concentration of energy upon stimulated localities, with the resulting renewal by movements of conditions that are pleasure-giving and beneficial, and the subsequent repetitions of the movements, is called the "circular reaction" (ref. 1, 2). It is the selective property which Romanes pointed out as characterizing and differentiating life. It characterizes the responses of the organism, however low in the scale, to all stimulations-even those of a mechanical and chemical (physico-genic) nature. Pfeffer has shown such a determination of energy toward the parts stimulated even in plants. And in the higher animals it finds itself exactly reproduced in the nervous reaction seen in imitation and-through the processes of association, substitution, etc.-in all the higher mental acts of intelligence and volition. These are developed phylogenetically as variations whose direction is constantly determined, by this form of adaptation in ontogenesis. If this be true-and the biological facts seem fully to confirm it-this is the adaptive process in all life, and this process is that with which the development of mental life has been associated.

\footnotetext{
${ }^{4}$ With the opposite (withdrawing, depressive affects) in injurious and painful conditions.
} 
It follows, accordingly, that the three forms of ontogenetic adaptation distinguished abovephysico-genetic, neuro-genetic, psycho-genetic-all involve the sort of response on the part of the organism seen in this circular reaction with excess discharge; and we reach one general law of ontogenetic adaptation and of Organic Selection. "The accommodation of an organism to a new stimulation is secured-not by the selection of this stimulation beforehand (nor of the necessary movements) - but by the reinstatement of it by a discharge of the energies of the organism, concentrated as far as may be for the excessive stimulation of the organs (muscles, etc.) most nearly fitted by former habit to get this stimulation again (in which the "stimulation" stands for the condition favorable to adaptation). After several trials the child (for example) gets the adaptation aimed at more and more perfectly, and the accompanying excessive and useless movements fall away. This is the kind of selection that intelligence does in its acquisition of new movements" (ref. 2, p. 179; ref. 6).

Accordingly, all ontogenetic adaptations are neurogenetic.5 The general law of "motor excess" is one of overproduction; from movements thus overproduced, adaptations survive; these adaptations set the determinate direction of ontogenesis; and by their survival the same determination of direction is set in phylogenesis also.

The following quotation from an earlier paper (ref. 7) will show some of the bearings of this position:

"That there is some general principle running through all the adaptations of movement which the individual creature makes is indicated by the very unity of the organism itself. The principle of Habit must be recognized in some general way which will allow the organism to do new things without utterly undoing what it has already acquired. This means that old habits must be substantially preserved in the new functions; that all new functions must be reached by gradual modifications. And we will all go further and say, I think, that the only way that these modifications can be got at all is through some sort of interaction of the organism with its environment. Now, as soon as we ask how the stimulations of the environment can produce new adaptive movements, we have the answer of Spencer and Bain-an answer directly confirmed, I think, without question, by the study both of the child and the adult-i.e., by the selection of fit movements from excessively produced movements, that is, from movement variations. So granting this, we now have the further question: How do these movement variations come to be produced when and where they are needed? ${ }^{6}$ And with it, the question: How does the organism keep those movements going which are thus selected, and suppress those which are not selected?

"Now these two questions are the ones which the biologists fail to answer. But the force of the facts leads to the hypotheses of "conscious force," "selfdevelopment" of Henslow and "directive tendency" of the American school-all aspects of the new Vitalism which just these questions and the facts which they rest upon are now forcing to the front. Have we anything definite, drawn from the study of the individual on the psychological side, to substitute for these confessedly vague biological phrases? Spencer gave an answer in a general way long ago to the second of these questions, by saying that in consciousness the function of pleasure and pain is just to keep some actions or movements going and to suppress others.

"But as soon as we enquire more closely into the actual working of pleasure and pain reactions, we find an answer suggested to the first question also, i.e., the question as to how the organism comes to make the kind and sort of movements which the environment calls for-the movement variations when and where they are required. The pleasure or pain produced by a stimulus - and by a movement also, for the utility of movement is always that it secures stimulation of this sort or that-does not lead to diffused, neutral, and characterless movements, as Spencer and Bain suppose; this is disputed no less by

\footnotetext{
${ }^{5}$ Barring, of course, those violent compelling physical influences under the action of which the organism is quite helpless.

${ }^{6}$ This is just the question that Weismann seeks to answer (in respect to the supply of variations in forms which the paleontologists require), with his doctrine of 'Germinal Selection' (Monist, Jan., 1896). Why are not such applications of the principle of natural selection to variations in the parts and functions of the single organism just as reasonable and legitimate as it is to variations in separate organisms? As against "germinal selection," however, I may say, that in the cases in which ontogenetic adaptation sets the direction of survival of phylogenetic variations (as held in this paper) the hypothesis of germinal selection is in so far unnecessary. This view finds the operation of selection on functions in ontogeny the means of securing "variations when and where they are wanted;" while Weismann supposes competing germinal units.
} 
James Mark Baldwin

the infant's movements than by the actions of unicellular creatures. There are characteristic differences in vital movements wherever we find them. Even if Mr. Spencer's undifferentiated protoplasmic movements had existed, natural selection would very soon have put an end to it. There is a characteristic antithesis in vital movements always. Healthy, overflowing, outreaching, expansive, vital effects are associated with pleasure; and the contrary, the withdrawing, depressive, contractive, decreasing, vital effects are associated with pain. This is exactly the state of things which the theory of selection of movements from overproduced movements requires, i.e., that increased vitality, represented by pleasure, should give the excess movements, from which new adaptations are selected; and that decreased vitality represented by pain should do the reverse, i.e., draw off energy and suppress movement. ${ }^{7}$

"If, therefore, we say that here is a type of reaction which all vitality shows, we may give it a general descriptive name, i.e., the "Circular Reaction," in that its significance for evolution is that it is not a random response in movement to all stimulations alike, but that it distinguishes in its very form and amount between stimulations which are vitally good and those which are vitally bad, tending to retain the good stimulations and to draw away from and so suppress the bad. The term 'circular' is used to emphasize the way such a reaction tends to keep itself going, over and over, by reproducing the conditions of its own stimulation. It represents habit, since it tends to keep up old movements; but it secures new adaptations, since it provides for the overproduction of movement variations for the operation of selection. This kind of selection, since it requires the direct cooperation of the organism itself, I have called 'Organic Selection."

The advantages of this view seem to be somewhat as follows:
1. It gives a method of the individual's adaptations of functions which is one in principle with the law of overproduction and survival now so well established in the case of competing organisms.

2. It reduces nervous and mental evolution to strictly parallel terms. The intelligent use of phylogenetic variations for functional purposes in the way indicated, puts a premium on variations which can be so used, and thus sets phylogenetic progress in directions of constantly improved mental endowment. The circular reaction which is the method of intelligent adaptations is liable to variation in a series of complex ways which represent phylogenetically the development of the mental functions known as memory, imagination, conception, thought, etc. We thus reach a phylogeny of mind which proceeds in the direction set by the ontogeny of mind, ${ }^{8}$ just as on the organic side the phylogeny of the organism gets its determinate direction from the organism's ontogenetic adaptation. And since it is the one principle of Organic Selection working by the same functions to set the direction of both phylogenies, the physical and the mental, the two developments are not two, but one. Evolution is, therefore, not more biological than psychological (ref. 2, chap. $\mathrm{x}$, xi, and especially pp. 383-388).

3. It secures the relation of structure to function required by the principle of "use and disuse" in ontogeny.

4. The only alternative theory of the adaptations of the individual are those of "pure chance," on the one hand, and a "creative act" of consciousness, on the other hand. Pure chance is refuted by all the facts which show that the organism does not wait for chance, but goes right out and effects new adaptations to its environment. Furthermore, ontogenetic adaptations are determinate; they proceed in definite progressive lines. A short study of the child will disabuse any man, I think, of the "pure chance"

\footnotetext{
${ }^{7}$ It is probable that the origin of this antithesis is to be found in the waxing and waning of the nutritive processes. "We find that if by an organism we mean a thing merely of contractility or irritability, whose round of movements is kept up by some kind of nutritive process supplied by the environment - absorption, chemical action of atmospheric oxygen, etc.- - and whose existence is threatened by dangers of contact and what not, the first thing to do is to secure a regular supply to the nutritive processes, and to avoid these contacts. But the organism can do nothing but move, as a whole or in some of its parts. So then if one of such creatures is to be fitter than another to survive, it must be the creature which by its movements secures more nutritive processes and avoids more dangerous contacts. But movements towards the source of stimulation keep hold on the stimulation, and movements away from contacts break the contacts, that is all. Nature selects these organisms; how could she do otherwise? . . . We only have to suppose, then, that the nutritive growth processes are by natural selection drained off in organic expansions, to get the division in movements which represents this earliest bifurcate adaptation." (ref. 2, p. 201).

${ }^{8}$ Prof. C. S. Minot suggests to me that the terms "ontopsychic" and "phylopsychic" might be convenient to mark this distinction.
} 
theory. But the other theory which holds that consciousness makes adaptations and changes structures directly by its fiat, is contradicted by the psychology of voluntary movement (ref. 4, 6, 7). Consciousness can bring about no movement without having first an adequate experience of that movement to serve an occasion as a stimulus to the innervation of the appropriate motor centers. "This point is no longer subject to dispute; for pathological cases show that unless some adequate idea of a former movement made by the same muscles, or by association some other idea which stands for it, can be brought up in mind the intelligence is helpless. Not only can it not make new movements; it can not even repeat old habitual movements. So we may say that intelligent adaptation does not create coordinations; it only makes functional use of coordinations which were alternatively present already in the creature's equipment. Interpreting this in terms of congenital variations, we may say that the variations which the intelligence uses are alternative possibilities of muscular movement" (ref. 4). So the only possible way that a really new movement can be made it by making the movements already possible so excessively and with so many varieties of combination, etc., that new adaptations may occur.

5. The problem seems to me to duplicate the conditions which led Darwin to the principle of natural selection. The alternatives before Darwin were "pure chance" or "special creation." The law of "overproduction with survival of the fittest" came as the solution. So in this case. Let us take an example. Every child has to learn how to write. If he depended upon chance movements of his hands he would never learn how to write. But on the other hand, he can not write simply by willing to do so; he might will forever without effecting a "special creation" of muscular movement. What he actually does is to use his hand in a great many possible ways as near as he can to the way required; and from these excessively produced movements, and after excessively varied and numerous trials, he gradually selects and fixes the slight successes made in the direction of correct writing. It is a long and most laborious accumulation of slight Organic Selections from overproduced movements (ref. for handwriting in detail, 2, chap. v; also 2, pp. 373, ff.).

6. The only resort left to the theory that consciousness is some sort of an actus purus is to hold that it directs brain energies or selects between possible alternatives of movement; but besides the objection that it is as hard to direct movement as it is to make it (for nothing short of a force could release or direct brain energies), we find nothing of the kind necessary. The attention is what determines the particular movement in developed organisms, and the attention is no longer considered an actus purus with no brain process accompanying it. The attention is a function of memories, movements, organic experiences. We do not attend to a thing because we have already selected it, or because the attention selects it; but we select it because we-consciousness and organism - are attending to it. "It is clear that this doctrine of selection as applied to muscular movement does away with all necessity for holding that consciousness even directs brain energy. The need of such direction seems to me to be as artificial as Darwin showed the need of special creation to be for the teleological adaptations of the different species. This need done away, in this case of supposed directive agency as in that, the question of the relation of consciousness to the brain becomes a metaphysical one, just as that of teleology in nature became a metaphysical one; and it is not to much profit that science meddles with it. And biological as well as psychological science should be glad that it is so, should it not?" (ref. 6; and on the metaphysical question, ref. 7).

\section{V.}

A word on the relation of this principle of Organic Selection to Natural Selection. Natural Selection is too often treated as a positive agency. It is not a positive agency; it is entirely negative. It is simply a statement of what occurs when an organism does not have the qualifications necessary to enable it to survive in given conditions of life; it does not in any way define positively the qualifications which do enable other organisms to survive. Assuming the principle of Natural Selection in any case, and saying that, according to it, if an organism does not have the necessary qualifications it will be killed off, it still remains in that instance to find what the qualifications are which this organism is to have if it is to be kept alive. So we may say that the means of survival is always an additional question to the negative statement of the operation of natural selection. 
This latter question, of course, the theory of variations aims to answer. The positive qualifications which the organism has arise as congenital variations of a kind which enable the organism to cope with the conditions of life. This is the positive side of Darwinism, as the principle of Natural Selection is the negative side.

Now it is in relation to the theory of variations, and not in relation to that of natural selection, that Organic Selection has its main force. Organic Selection presents a new qualification of a positive kind which enables the organism to meet its environment and cope with it, while natural selection remains exactly what it was, the negative law that if the organism does not succeed in living, then it dies, and as such a qualification on the part of the organism, Organic Selection presents several interesting features.

1. If we hold, as has been argued above, that the method of Organic Selection is always the same (that is, that it has a natural method), being always accomplished by a certain typical sort of nervous process (i.e., being always neuro-genetic), then we may ask whether that form of nervous process-and the consciousness which goes with it-may not be a variation appearing early in the phylogenetic series. I have argued elsewhere (ref. 2, pp. $200 \mathrm{ff}$. and $208 \mathrm{ff}$.) that this is the most probable view. Organisms that did not have some form of selective response to what was beneficial, as opposed to what was damaging in the environment, could not have developed very far; and as soon as such a variation did appear it would have immediate preeminence. So we have to say either that selective nervous property, with consciousness, is a variation, or that it is a fundamental endowment of life and part of its final mystery. "The intelligence holds a remarkable place. It is itself, as we have seen, a congenital variation; but it is also the great agent of the individual's personal adaptation both to the physical and to the social environment" (ref. 4).

"The former (instinct) represents a tendency to brain variation in the direction of fixed connections between certain sense-centers and certain groups of coordinated muscles. This tendency is embodied in the white matter and the lower brain centers. The other (intelligence) represents a tendency to variation in the direction of alternative possibilities of connection of the brain centers with the same or similar coordinates muscular groups. This tendency is embodied in the cortex of the hemispheres" (ref. 4).

2. But however that may be, whether ontogenetic adaptation by selective reaction and consciousness be considered a variation or a final aspect of life, it is a life-qualification of a very extraordinary kind. It opens a new sphere for the application of the negative principle of natural selection upon organisms, i.e., with reference to what they can do, rather than to what they are; to the new use they make of their congenital functions, rather than to the mere possession of the functions (ref. 2, pp. 202 f.). A premium is set on congenital plasticity and adaptability of function rather than on congenital fixity of function; and this adaptability reaches its highest in the intelligence.

3. It opens another field also for the operation of natural selection-still viewed as a negative principle-through the survival of particular overproduced and modified reactions of the organism, by which the determination of the organism's own growth and life-history is secured. If the young chick imitated the old duck instead of the old hen, it would perish; it can only learn those new things which its present equipment will permit-not swimming. So the chick's own possible actions and adaptations in ontogeny have to be selected. We have seen how it may be done by a certain competition of functions with survival of the fit. But this is an application of natural selection. I do not see how Henslow, for example, can get the so-called "self-adaptations"apart from "special creation" - which justify an attack on natural selection. Even plants must grow in determinate or "select" directions in order to live.

4. So we may say, finally, that Organic Selection, while itself probably a congenital variation (or original endowment) works to secure new qualifications for the creature's survival; and its very working proceeds by securing a new application of the principle of natural selection to the possible modifications which the organism is capable of undergoing. Romanes says: "it is impossible that heredity can have provided in advance for innovations upon or alterations in its own machinery during the lifetime of a particular individual." To this we are obliged to reply in summing up-as I have done before (ref. 2, p. 220)-we reach "just the state of things which Romanes declares impossible-heredity providing for the modification of its own machinery. Heredity not only leaves the future free for modifications, it 
also provides a method of life in the operation of which modifications are bound to come."

\section{VI.}

The Matter of Terminology.-I anticipate criticism from the fact that several new terms have been used in this paper. Indeed one or two of these terms have already been criticised. I think, however, that novelty in terms is better than ambiguity in meanings. And in each case the new term is intended to mark off a real meaning which no current term seems to express. Taking these terms in turn and attempting to define them, as I have used them, it will be seen whether in each case the special term is justified; if not, I shall be only too glad to abandon it.

Organic Selection.-The process of ontogenetic adaptation considered as keeping single organisms alive and so securing determinate lines of variation in subsequent generations. Organic Selection is, therefore, a general principle of development which is a direct substitute for the Lamarckian factor in most, if not in all instances. If it is really a new factor, then it deserves a new name, however contracted its sphere of application may finally turn out to be. The use of the word "Organic" in the phrase was suggested from the fact that the organism itself cooperates in the formation of the adaptations which are effected, and also from the fact that, in the results, the organism is itself selected; since those organisms which do not secure the adaptations fall by the principle of natural selection. And the word "Selection" used in the phrase is appropriate for just the same two reasons.
Social Heredity. - The acquisition of functions from the social environment, also considered as a method of determining phylogenetic variations. It is a form of Organic Selection but it deserves a special name because of its special way of operation. It is really heredity, since it influences the direction of phylogenetic variation by keeping socially adaptive creatures alive while others which do not adapt themselves in this way are cut off. It is also heredity since it is a continuous influence from generation to generation. Animals may be kept alive let us say in a given environment by social cooperation only; these transmit this social type of variation to posterity; thus social adaptation sets the direction of physicalphylogeny and physical heredity is determined in part by this factor. Furthermore the process is all the while, from generation to generation, aided by the continuous chain of extra-organic or purely social transmissions. Here are adequate reasons for marking off this influence with a name.

The other terms I do not care so much about. "Physico-genetic," "neuro-genetic," "psycho-genetic," and their correlatives in "genic," seem to me to be convenient terms to mark distinctions which would involve long sentences without them, besides being self-explanatory. The phrase "circular reaction" has now been welcomed as appropriate by psychologists. "Accommodation" is also current among psychologists as meaning single functional adaptations, especially on the part of consciousness; the biological word "adaptation" refers more, perhaps, to racial or general functions. As between them, however, it does not much matter.?

\footnotetext{
${ }^{9}$ I have already noted in print (ref. 4 and 6) that Prof. Lloyd Morgan and Prof. H. F. Osborn have reached conclusions similar to my main one on Organic Selection. I do not know whether they approve of this name for the "factor;" but as I suggested it in the first edition of my book (April, 1895) and used it earlier, I venture to hope that it may be approved by the biologists.
} 